\title{
RESEARCH INTO LABOUR, EMPLOYMENT AND WORK IN NEW ZEALAND: OVERVIEW OF THE TWELFTH CONFERENCE
}

\author{
Philip S. Morrison \\ School of Geography, Environment and Earth Sciences \\ Victoria University of Wellington
}

This twelfth Labour, Employment and Work Conference generated papers from a wide set of contributions: researchers from government departments, academics from each of the country's eight universities, researchers from a range of private research organisations as well as practitioners from industry This year, with a buoyant economy and a twenty year low in unemployment, much of the emphasis was on the quality rather than the quantity of work; stress, injury, the meaning of 'career' and the quality of working life as well as job mobility all received specific attention.

With labour force participation rates at an historical high. attention still turned to those who were (still) not participating, those who even in such conditions remain underemployed and unemployed. The issues of recruiting skilled worker and training went hand in hand with a continued concern for under participation among the disabled, young Maori and Pacific Island populations, together with questions about how geographic context affects participation and how the operation of other markets like housing constrains job mobility.

One of the real advantages of the involvement of government researchers in these LEW conferences is their ability to draw on their own administrative data sets, on data which might otherwise be inaccessible to the wider research community. The example highlighted in these proceedings is LEED, the Linked Employer-Employee Dataset. LEED was created by linking a longitudinal employer series from the Statistics New Zealand Business Frame to a longitudinal series of Employer Monthly Schedule payroll data from Inland Revenue. A special session of LEW12 was devoted to the development and application of LEED to a number of contemporary labour market questions.

Much of our economic growth over the last decade has been because we've been able to more fully utilise a growing labour force, helped in part by the continued expansion of those in the prime working ages. As we progress through the 2000s the scope for increased growth by existing labour is limited (even considering migration) and attention is now increasingly focused on the way we can use labour more efficiently. Although receiving considerable media attention in 2006, only limited attention was paid in this conference to productivity issues. The papers on measurement and work place productivity remain central to the debate. Weighting productivity issues against quality of work life is one of the challenges that characterise research in a buoyant labour market and hopefully our next conference in 2008 will help us better conceptualise the nature of the trade offs which are possible and the respective costs and benefits.

In the meantime, we have plenty to go on with. The following paragraphs summarise the main points raised by 86 authors whose work is published in the 52 papers in these proceedings. The summaries appear under the 17 subject headings provided. The aim, as always, is to encourage others to both question and build on these ideas, to network and collaborate in new research in the two years before we meet again in Wellington in late 2008.

The 17 headings are as follows; overview and keynote address, transition, employment realities and management, using Linked Employer-Employee Data (LEED), the minimum wage, immigration, "skills, jobs and the workforce', recruitment, unions, productivity, health sector, quality of worklife, 'sub-optimal and minority employment', training, youth, 'regions, settlement type and labour market participation', and finally stress and injury.

\section{Overview and keynote}

Joselyn Stroombergen's paper from Work Directions, Department of Labour, was presented by Paul Barker who began by referring to New Zealand's recent robust economic performance $-3.6 \%$ per annum on average since 1999. While the strong improvement in a wide array of labour market indicators was anticipated what had surprised many economic commentators was the continued strength of the labour market in the face of the recent slowing economic activity. With labour utilisation now stretched to the limit if we want to maintain economic growth at present levels then it is clear that we will need to substantially lift our level of labour productivity growth. At the same time, making such a transition to a more productive economy while maintaining the gains achieved in labour utilisation will be challenging.

This year's Keynote speaker, Stephen Bevan from The Work Foundation in London in the United Kingdom, spoke on Knowledge Cities, a concept which becomes more useful when widened beyond the simple definition based around ICT and biotechnology to include the creative industries, the public sector and manufacturing. With this broader perspective and with the right policies in place, there is no reason, Bevan argued, why a 
knowledge economy should be characterised by growing inequality. Central here is the link between the knowledge economy and place - the concept of the Ideopolis - a sustainable knowledge intensive city that drives growth in the wider city-region.

\section{Transitions}

Brian Easton asks how globalisation changes local labour markets. He notes how in the nineteenth century there was a global labour market (for Europeans anyway) but that the twentieth century saw restrictions placed on the free flow of the population while goods, capital and technology markets became increasingly internationally mobile. Brian's main point is that there will have to be increased labour flows to deal with the need to care for the rich world's ageing population given that the demand for labour is being driven increasingly by the uneven demography of the developed and developing worlds.

Paul Callister and Jamie Newell from Victoria University of Wellington and Monitoring and Evaluation Research Associates (MERA) respectively, introduce the gender 'education transition' and ask what effect the increasingly proportion of women in tertiary education might have on the labour market. They observed that in 1994 (and when foreign students are excluded) there were $13 \%$ more women in the under 30 age group enrolled in degree courses than men. They observe how the cohorts that are part of this tertiary "education transition" are now a key part of the population that are forming couples or deciding to live on their own, establishing their careers and deciding whether to have children.

Philip Spier from the Department of Labour, describes the results from a study of 'occupational mobility' in New Zealand. Identifying the extent to which people are leaving the occupation for which they have trained improves our understanding of the contribution of occupational mobility makes to skill shortages. The structure of these transitions, and how training one occupation links to another, is of growing importance in understanding the flexibility of the contemporary workforce.

Prue Hyman from Victoria University of Wellington reported on progress in pay equity and equal employment opportunity in New Zealand. Her 2004 LEW paper argued that the most urgent priority was practical development and piloting of means of implementation of pay and employment equity. While noting that there are positive developments since then, including the establishment and work of the Pay and Employment Equity Unit in the Department of Labour, progress has been slow. Meanwhile carers and cleaners, where Maori and Pacific women predominate, still fight for a living wage even during this period when gender and ethnic mainstreaming held considerable sway. Government monitoring of pay equity and equal employment opportunity from outside therefore remains essential.

\section{Employment realities and management}

Rupert Tipples from Lincoln University and Nona Verwoerd shared some of their conceptual ideas on psychological contracts in dairy farming that will inform their 'Once-a-Day' milking research project. They review alternative research strategies for exploring the qualitative data that will be generated from their research.

Meryl McPherson from the Equal Employment Opportunities Trust considered the role of managers in work-life balance implementation. Using findings mainly from their recent Work-Life Balance Survey of New Zealand employers, Meryl looked at where New Zealand organisations are in terms in implementing work-life balance programmes. She drew additional information from her qualitative study of mothers' experience of combining paid work and parenting and concluded by suggesting how New Zealand organisations can improve outcomes from work-life balance initiatives by paying greater attention to the role of managers in the process.

\section{Using linked employer-employee data (LEED)}

This section of the conference was designed to allow those researchers inside and outside government to share findings from a new data source which uses longitudinal information from existing taxation and Statistics New Zealand sources to provide a range of information on the dynamics of the New Zealand labour market.

Rodney Jer, Ian McGregor and Tas Papadopoulos are members of the Statistics New Zealand team generating person-level statistics from LEED. They showed how LEED has allowed new statistics to be produced for the first time on income transitions, job tenure, multiple job holding and the self-employed, as well as new statistics at regional and industry detail not available from existing sources. The paper itself covers five main areas: people's sources of income, income transitions, income source spells, multiple job holding as well as new information on self-employment.

Sylvia Dixon and Sarah Crichton, from the Department of Labour and Statistics New Zealand respectively, ask just how successful benefit-to-work transitions have been in terms of the longer-term outcomes experienced by people who move from a working-age benefit to employment. Their study covers people, who over a period of two years, moved before and after the benefitto-work transition. They describe short-term and longerterm employment retention rates and earnings growth patterns, comparing the outcomes of their ex-beneficiary study population with those of non-beneficiaries who began a job in the same year. They examined the factors that are associated with more or less 'successful' outcomes, including personal characteristics, prior employment experiences, the timing and nature of the benefit-to-work transition, and the characteristics of posttransition employers.

David Maré and Dean Hyslop, from Motu Economic and Public Policy Research and The Treasury respectively, use the linked employer-employee data to derive and analyse estimates of two-way worker and firm fixed effects in order to understand the heterogeneity of job earnings rates. Over the period April 1999-March 2005 their fixed effects estimates reflect the portable earnings premium that each worker receives in whichever firm they work for, and a time-invariant premium that each firm pays to all the workers it employs. From these 
results it is possible to tell them how much of the variation in job earnings rates is attributable to observable worker demographic factors (age and gender), unobserved worker effects and unobserved firm effects. They also tell how much compositional change occurred during this period of substantial employment growth and explain the aggregate pattern of sorting of workers and firms across jobs.

Terry Moore from Statistics New Zealand uses the LEED data to undertake a longitudinal analysis of benefit to work transitions. He asks what factors affect the probability that a person makes a transition from benefit to employment. He estimates the probability of such a transition given information on age, sex, and most recent occupation and industry. His principal finding is that age and sex has the most significant impact on transitions from benefit to work and that the difference between sexes is greatest for under 35 year olds. He also found differences by industry and occupation as well as some regional differences and time effects.

Eleanor Guzman-Posadas from Statistics New Zealand used LEED data to explore aggregate as well as and individual variations in wage earnings. Random effects models were investigated to identify fixed population effects as well as to help understand stochastic processes attributed to individual employee variations. She found that wages varied significantly across region of residence. industry, age groups and gender and random intercept adjustments provide an effective alternative in exploring wage earning variability over time.

Tim Maloney from the University of Auckland used the same data to analyse job mobility. His expectation was that the movement of workers between jobs would play an important role in determining both the average level and overall dispersion in earnings in an economy. However he found that individuals changing jobs receive monthly earnings that were, on average, below the earnings received by individuals who did not change jobs. What was important was a move to a firm with more employees and that pays higher average earnings to all its employees, for it was this combination that resulted in a substantial increase in individual earnings of movers. Finally, earnings growth was found to be negatively related to the time interval between jobs, as well as the initial earnings of the individual.

\section{Minimum wage}

Michael Barry and Peter Brosnan from the Industrial Relations Department of Griffith University offered an Asia Pacific perspective on minimum wage systems. They point out that some Pacific countries are among the pioneers in establishing minimum wages. The paper discusses the many aims that minimum wages are designed to achieve including promoting social justice, alleviating poverty, promoting economic development, setting benchmarks for other wages and social security payments, and controlling inflation. However the Asia Pacific region has only a small number of countries with adequate minimum wage systems and there are many deficiencies. They often do not cover all workers, are often set at unrealistically low levels, or are enforced inadequately. Their paper discusses the causes of these deficiencies and the consequences of them for those who rely on minimum wages.

Jason Timmins from the Department of Labour identifies minimum wage workers in New Zealand. He notes how the New Zealand minimum wage rate has recently experienced a sustained period of growth that looks set to continue under the current Labour-led government. Since 2002 the adult minimum wage rate increased by $28 \%$ from $\$ 8$ an hour to the current rate of $\$ 10.25$ outstripping the $15 \%$ increase in average wages. Jason uses the New Zealand Household Labour Force Survey and its Income Supplement to identify minimum wage workers and describe their demographic and job characteristics. As well as changes in their characteristics between 2002 and 2006. To provide a richer picture of low-paid work in New Zealand he compares the characteristics of minimum wage workers with individuals earning below the minimum wage and just above the minimum wage.

\section{Immigration}

Paul Merwood, from the Department of Labour evaluates those work policies that provide a pathway to permanent residence in New Zealand. The purpose of Paul's research to describe the characteristics of migrants approved through the work to residence policies, the characteristics of accredited employers and the migrants they employ, and the transition patterns from temporary to permanent residence. The research involves a quantitative analysis of the department's administrative data, an online survey of accredited employers, and qualitative interviews with policy stakeholders. He shows that over 4,000 migrants had been granted a work permit through these policies, and almost one third had made the transition to permanent residence. He found that the Talent Visa (Accredited Employers) policy enabled employers to expedite the recruitment of overseas workers, and the work to residence aspect was an attractive incentive for potential migrants.

Nicola North from The University of Auckland, explored employers' attitudes and practices on the hiring of immigrants. A total of 246 questionaries were returned from the "Top $500^{\circ}$ list of companies and those randomly elected from the Yellow Pages. Follow-up unstructured interviews were conducted with a sub-set of 19 employers. The results showed that over $70^{\circ}$ of companies employed immigrants and those companies were largely positive about their immigrant employees. When recruiting, employers were influenced to a large extent by previous New Zealand work experience and to a slightly lesser extent by New Zealand qualifications. When practices of recruiting were discussed in the interviews, a complex web of reasoning on the part of employers emerged that had the end result of severely disadvantaging immigrant applicants relative to New Zealander applicants, particularly applicants from certain countries and cultures of origin. The issues raised by employers that were used to the detriment of immigrant applicants included English language and communication. cultural fit, and the manner in which immigrants approached companies for employment. Interview participants also commented on how immigrants could make themselves more employable, advice that 
paradoxically highlighted the Catch-22 situation many immigrant applicants find themselves in. The results are discussed in the context of international competition for skill and workforce diversity.

Andrea Garnham from Auckland University is exploring the entrepreneurial activities of refugees in New Zealand for her PhD. Official data shows that 86 percent of refugees are still unemployed after five-years residency in New Zealand, frequently as a result of discrimination and the so-called "lack of transferable skills". The transition of refugees to becoming entrepreneurial small business owners is seen as one way of escaping welfare dependence and workplace discrimination. Andrea begins with a critique of relevant literature and introduces a set of synergistic definitions. Aspects of Valtonen's integration model and the Human Capabilities Framework are combined to develop a new framework, detailing a possible process of refugees becoming entrepreneurs.

Juthika Badkar and Vasantha Krishnan from the Department of Labour and Paul Callister from Victoria University of Wellington explore the changing patterns of gendered skilled migration into New Zealand. Their paper looks at trends in the proportion of female and male principal applicants who have migrated to New Zealand through the General Skills and Skilled Migrant Category from 1997/98 to 2005/06. changes in source countries and gender differences in outcomes for skilled migrants. They found that from 1997:98 to 2001/02 the number of female and male migrants entering New Zealand through the skilled categories increased exponentially. Although the proportion of female to male migrants for the skilled categories was low $(1: 2)$ throughout the 199798 to 200506 period. the number of women to men from certain source countries (for example. Canada. China. Ireland. Philippines, Japan and France) increased or remained high during this period. Results from the Department of Labour's Settlement Experiences Feedback Survey (survey sent to Skilled Business stream migrants) shows that while the majority of both female and male principal applicants were employed $\left(94^{\circ} \circ\right)$, there were substantial differences in occupation, industry and incomes between female and male skilled migrants.

\section{Skills, jobs and the workforce}

Ram SriRamaratnam, Kevin Zhang, and Andrew Whiteford. from the Department of Labour outline the methods they use in forecasting employment by occupation and industry as well as by skill level, by sector and region in New Zealand. They point out how often forecasts are made of the demand for labour. both additional and replacement demand. the latter often surpassing the former due to the present demographic composition of the labour force. In order to assess likely futuie shortages (or surplus) of labour. knowledge of the current supply (not always known with eertainty as in the case of seasonal labour) and an understanding of future supply is required. They outline the approaches and methodology likely to be applicable in forecasting labour demand as well as the required level of accuracy. They discuss the relevance of forecasts in relation to national. sectoral, regional and seasonal labour market outcomes.
Some preliminary and provisional results are presented as illustrations of likely outcomes.

Mark Williams from Massey University and Alan Williams address the way in which tomorrow's skill needs can be addressed through pre-employment teaching programmes in New Zealand schools. The paper reviewed work in progress on a teaching programme for students whose formal education tends to terminate at the secondary school level. The perception of need is based initially on the structural shifts taking place in industrial demographics which postulate a decline in the new entrant replacement rate and a rising dependence on indigenous labour supply. This trend has raised the need to reconsider the New Zealand case, using Torsten Husen's seminal concept of the reserve of talent. It proposes a triadic model as a possible strategic tool, in which a given school and its local community, together with a designated employing firm in a specific category of skilled work, collaborate in a combination of teachinglearning and practical exercises. Their intention is to raise the level of information available to job-seekers, employing firms as well as the socio-economic perception of employment opportunities within the community. The paper uses as an example, a working model of the civil engineering industry, which has been the focus of some preliminary testing.

Serious skill shortages in New Zealand continue to be among the most severe in the OECD. Anne de Bruin Anne, Paul Spoonley, Eva McLaren and Patrick Baron from Massey University`s Auckland campus ask whether the modern apprenticeship scheme is the answer. Drawing on qualitative data from two studies of employers conducted under the auspices of the interdisciplinary, FRST-funded Labour Market Dynamics Research Programme they argue that the Modern Apprenticeship Scheme, is only a small step forward in addressing what appears to be an ongoing skills crisis in the traditional trades sector. New Zealand employers they argue remain generally pessimistic that these measures will adequately address the skills deficit, in the short as well as longer term.

Nicky Murray from CareerForee (Community Support Services ITO) in Christchurch takes a critical look at the term 'workforce development'. Often used as a 'catchall phrase. Nicky argues that the term has quite different meanings and implications, depending upon the user and the context. In this exploratory paper. Nicky traces the genesis of the term. noting its theoretical underpinnings in systems thinking. She then discusses some of the drivers behind the evolution of the concept, and examine why it appears to have supplanted notions of workforce or manpower 'planning". Using the health and disability sector as a case study. Nicky highlights some of the differences in how the term is used, and discusses the implications. She then asks if the term does actually translates into actions that 'develop' the workforce.

Andrew Whiteford. from the Department of Labour asks how well we have addressed our shortage of trades persons. In 2005 the Department of Labour published an overview of skill shortages in the trade occupations and outlined the major reasons for those shortages. These 
included the low number of people entering the trades in the 1990 s, net migratory outflows in late and early 2000 s, low training levels in the early 2000s. This current paper revisits these issues and discusses progress in addressing the shortage of tradespersons.

\section{Recruitment}

Alan Coetzer and Jacqui Campbell from Massey University's Wellington Campus explore the complementarities between recruitment and selection practices and new employee learning in New Zealand's small and medium sized enterprises. Data were collected through interviews with mainly owners/managers of 60 firms employing up to 50 staff. Analysis of the interviews suggests that the recruitment and selection practices used by some owners/managers had unintended positive effects on newcomers' learning. Trusted current employees were encouraged to recruit new staff from their networks of family and friends. Sponsors often took the initiative in supporting newcomers on their pathways of work-related learning. Also, some owners/managers used selection methods that involved candidates demonstrating their skills on-the-job, through work samples or work trials. These selection methods had the effect of yielding information about candidates' learning needs. The authors argue that researchers should pay less attention to traditional Human Resource Management (HRM) functions and start to focus on complementarities that might exist among HRM practices. Such a focus, they argued, may be more consistent with the ways owners/managers view managing human resources.

Eljon Fitzgerald and Eva McLaren from Massey University's Auckland and Palmerston North campuses respectively, address Te Ara Māori - pathways to recruitment, training, retention and business growth. Their analysis of Māori employers is based on the experiences of 30 Māori employers involved in a variety of industries across New Zealand. The analysis focuses on employment-related issues that might affect the advancement of a growing Māori economy. The Māori employers interviewed for this project demonstrated greater business confidence about the future of their organisations than non-Māori employers surveyed in the same study.

\section{Unions}

Alexander John Murrie, Barry Foster, Glyn Jeffrey, from Massey University in Palmerston North respectively, consider the role of employers in the formation of new unions under the Employment Relations Act 2000. Their paper reports on the formation of new, predominantly workplace based unions or New Unions under the Employment Relations Act 2000 (ERA). Specifically they question whether employers actively support and facilitate the formation of New Unions and whether they represent an independent form of employee representation. To date scholars have argued that employers play a significant, if not dominant, role in New Union formation that limits their ability to act independently. Some have questioned their status as genuine unions, and implied that many represent a form of de-collectivist strategy that deliberately seeks to undermine more genuine union organisations, through the formation of tame or company unions. This paper argues that New Union formation is an employee driven phenomenon, and that little evidence of employers deliberately precipitating, or dominating, the formation process can be found. New Unions operate independently of employers whose involvement is more likely to reflect an acceptance of workers legal right to organise collectively, established by the ERA, not a deliberate attempt to undermine existing unions.

Ian McAndrew, from the University of Otago, report on a 'stocktake' of union-management workplace partnership practices and behaviours in New Zealand. His study offers empirical insights into the attitudes and behaviours of New Zealand employers and union officials in singleemployer collective bargaining relationships collective bargaining, other consultative measures, and collaborative versus competitive approaches to relationships with one another. They contrast their findings with a 2005 study which found that the penetration of partnership practices has been sporadic and/or experimental, set in an environment that is oftentimes abrasive to the concept. In many workplaces where collective bargaining has existed for a significant period, both unions and management are adopting some key features of a partnership approach. The study concluded that prospects for further penetration of partnership behaviours in unionized firms are positive as the attitudes of many officials on both sides are relatively open to the approach and to the practices it encompasses.

\section{Productivity}

Thomas McNaughton, from Statistics New Zealand, considers a quality-adjusted measure of productivity in recognition that workers are not homogenous and have different productivity levels. Not only does this approach provide a more accurate measure of labour inputs but it can also provide insight into the effects that changes in labour composition have on productivity. Quality adjustment is undertaken by cross-classifying labour according to various characteristics, such as educational attainment and training, with the relative productivity levels of different groups being reflected through a weighting process. This paper evaluates the various theories behind quality-adjustment, the success of its international applications, and the potential for an internationally comparable adjustment to be introduced into the current productivity series.

Felicity Lamm, Claire Massey and Martin Perry, from the University of Auckland and Massey University respectively, respond to the Department of Labour's Workplace Productivity Working Group encouragement of debate on workplace productivity. Their two studies identified key indicators that enhance workplace productivity and performance - namely processes, systems, people and organisational culture and, more interestingly, draw attention to the rubric of performance, workplace productivity and the health and safety of workers. The findings indicated that in practice, efficiency increased both through innovation and shifts into activities with higher value added than those conducted in the past. However, there is an inherent tension within these and other similar studies that cannot 
easily be resolved. One on hand, employers are striving to obtain increased worker performance and gain more productivity while on the other hand they are driving their employees to work longer, harder and more effectively what are often in extremely hazardous conditions. In such circumstance effort to increase productivity can have contradictory results.

\section{Health Sector}

Maggie Roe-Shaw of the Department of Labour considers the realities of professional socialisation into the physiotherapy workplace. Her paper illuminates the professional socialisation process in a variety of physiotherapy workplaces through engagement with a range of facilities and participants including new graduates, physiotherapy managers and physiotherapists that are more experienced. Maggie explores the being and becoming a physiotherapist, paying special attention to the workplace in the professional socialisation process. She examines positive workplace experiences for recent graduates, and identifies links between these experiences. professional career structures, and the attrition rate from the profession. She questions how well physiotherapists are prepared for the realities of the workplace. While this paper includes a theoretical model of professional socialisation. the focus is on the lived experience of physiotherapists in the context of practice, undergraduate and postgraduate education, and the constantly changing healthcare workplace through globalisation and economic rationalisation.

Nicola North, from the University of Auckland and colleagues' report on the use of temporary nurse mechanisms by New Zealand's District Health Boards. Nursing shortages which are a concern receives research attention globally because of the high costs of turnover and retention. A national study on the costs of nursing turnover in New Zealand public hospitals was conducted between 2004-2006, revealing average annual turnover rates of $38.16^{\circ} \%$, ranging between $13.83^{\circ}$ and $73.17^{\circ}$. In the context of the study it was assumed that temporary cover mechanisms were mainly to cover vacancies and occasional unplanned contingencies such as influenza affecting staff, and higher than normal demands for nursing work. As such the cost of temporary cover was a cost of turnover. An unexpected finding of the study however was that temporary cover mechanisms were widely used. including when actual staff numbers were equal to or exceeded budgeted FTE, and no consistent relationship with vacancies was evident. It was concluded that management of the nursing resource was driven by cost. not strategic, considerations.

\section{Quality of working life}

Kim Allen from the Department of Labour asks how decisions about caring and working are made and the

\footnotetext{
I Frances Hughes from University of Technology Sydney: Erling Rasmussen, Department of Management and Employment. The University of Auckland: Mary Finlayson, School of Nursing. The University of Auckland: Toni Ashton. School of Public Health. The University of Auckland: Taima Campbell, Nursing and Midwifery. Auckland District Health Board: Sharon Tomkins, School of Nursing, The University of Auckland
}

factors that influence people's caring decisions surrounding paid work. Fifty qualitative interviews were undertaken with people with primary caring responsibilities for children and/or adults, or in a few cases, shared caring responsibility with their partner. Kim found that multiple factors influenced people's choices about paid work, and that different approaches suited different people in different situations. Participants made decisions that, as far as possible, balanced their beliefs about caring with their commitment to work and their need for intellectual satisfaction, social contact and money. Their decisions were based on their personal preferences, rather than on information about financial benefits or services that might support them in their role. The research also highlighted the importance of providing an environment that supports people's choices to be involved in employment, and to care for their loved ones. The study has identified a number of areas for further work.

Zeenobiyah Hannif from the University of Wollongong considers the work life experiences of older workers in a New Zealand call centre. She notes how older workers have experienced significant changes in their labour market experiences over the last few decades. Her paper examines the work life experiences of 10 older workers where 31 percent of the call centre workforce comprises those in the 50 years plus age groups. This low-end call centre, characterised by low skilled-low pay work. receives little in the way of investment in human resources and the older workforce is the workforce of choice given the levels of commitment, and length of service that can be derived. For these workers in turn, commitment appears to be a product of the paucity of work opportunities elsewhere. They are reluctant participants forced into this work environment out of necessity and financial hardship rather than any particular attraction to the work or the industry itself. The result is the emergence of a sub-culture of low morale, dithering motivation and increasing levels of resentment. Reporting on the individual accounts of aged workers Zeenobiyah raises some contentious issues relating to the employment of aged workers, including the older workers, their lack of choice and their self selection into low quality jobs, and their motivations.

\section{Vivienne Hunt, Erling Rasmussen, and Felicity Lamm} from the University of Auckland also report on call centre employment. They begin by noting that call centres are still a growing phenomenon worldwide attracting a mainly female workforce. The mainly comparative nature of the call eentre research is problematic however because of their heterogeneity. The comparisons do not take into account the wider perspective of the organisation, the sector or the division of labour. Their own findings from six case studies shows mixed evidence but clearly demonstrates that work outcomes in New Zealand call centres can be very positive for many of the women who work there.

Chris Hector, from the University of Waikato was involved in constructing a questionnaire the quality of working life, and the extent to which members of the workforee feel that their working lives have got better or worse in recent years. In particular, 14 of these questions 
specifically probe the nature of recent ICT adoption and any changes to workplace organization resulting from new ICTs and any perceived effects on the quality of working life.

\section{Suboptimal and minority employment}

Ann Dupuis from Massey University's Auckland campus and Nick Taylor from Taylor Baines Associates present a framework for examining sub-optimal employment. They begin by noting how demographic projections for New Zealand indicate there will be major labour shortages in the future which will not be met through either natural increase in population or immigration. At present, there is inadequate information about the labour market and employment due in part to the way many employmentrelated measures are defined. The importance given to two measures in particular - the official unemployment and the labour force participation rate - provide an incomplete picture of the complex and increasingly diverse patterns of employment. In response their paper provides a preliminary conceptualisation of sub-optimal employment, which demonstrates the extent of employment statuses could be considered sub-optimal.

Jamie Baines and Jamie Newell from Taylor Baines \& Associates and Monitoring \& Evaluation Research Associates (MERA) respectively consider the pitfalls of monitoring minority labour market phenomena because labour markets are in a constant state of change, in terms of both scale and composition. Their comparison of various statistical data sets reveals substantial differences in estimates as data are disaggregated.

In a second paper the same two authors document the variation in multiple job holding rates amongst women with young children between 1981 and 2001. They use multiple job holding as an indicator of work-life balance observing how economic and career pressures on work life balance are highest in young adulthood when women are juggling entry into the work force, family formation and the costs of setting up their own households.

Jessica Harvey and Robbie Field from Heinz Wattie's Ltd address a recognition and rewards system in their organisation. The challenge for employers, they argue, is to identify and implement recognition and rewards programmes that are effective but not too complex and which support a working environment that improves motivation and staff morale, whilst at the same time impacting positively on organisational performance. Research into recognition and rewards programmes would indicate that there are a number of options available and that successful programmes and current approaches need to include certain fundamental requirements.

\section{Training}

William Cochrane, Michael Law and Gemma Piercy from the Centre University of Waikato raise a number of new research possibilities as they relate to industry training organisations. They note how the tertiary education reforms have placed considerable pressure on Industry Training Organisations (ITOs), which are now required to assume new roles as strategic leaders in skills and training needs for the industries under their coverage.
Their paper argues that these requirements can lead to productive relationships between ITOs and established research organizations. Specifically they report on research commissioned by the New Zealand Industry Training Organisation (NZITO), which covers dairy manufacturing, meat processing, and leather processing, in which they cover the impact of an ageing workforce, the impact of technological change and some of the consequences of the continuing integration of the global economy.

\section{Nicky Murray, Lucie Wenmakers and Toni Fraser} from the Industry Training Organisation Research Group, consider the role of leadership within industry training organisations and the relationship between policy and practice. The 41 Industry Training Organisations (ITOs) are charged with setting skill standards for their industries, with developing and making arrangements for the delivery of training, and its monitoring and assessment. Each is directed to ensuring that trainees attain the required skill standards. The increasing maturity and success of the industry training system is reflected in a recent addition to the Industry Training Act. This paper presents the approaches that two ITOs have taken in fulfilling their future skill needs strategic planning.

\section{Youth}

Jane Higgins and Janine Alfeld from Lincoln University describe the changing structure of youth labour markets in post-1984 New Zealand as part of a larger project exploring the school to post-school transition choices of New Zealand's first post-1984 generation. They gathered qualitative data from about one hundred young people in urban and rural locations in Otago/Southland, Canterbury and Auckland. They draw on the Morrison-Loeber framework in order to analyse census data from 1980 relating to the employment of young people (aged 15-24 years) across the project's various sites, in order to contextualise their qualitative data.

Rapid advances in information technology, changing workplace structures and labour shortages have increased the need for employees to be multi-skilled, adaptable and self-directed learners. However little is known about young people's beliefs and attitudes towards learning during their early years in the labour market. Robyn Mason from Massey University examines the impact of organisational environments on young workers' orientation to learn. Her paper illustrates the need to stimulate the learning orientations of less-qualified younger workers. A model for exploring the relationship between organisational environments and young workers' learning-related beliefs and attitudes is presented based on her proposed doctoral research.

Rebecca Osborne and Julie Warren from the Centre for Research, Evaluation and Social Assessment (CRESA) report on multiple job holding by young people. Their paper is based on structured face-to-face interviews with 73 people aged 18-34 years who worked in café/restaurant and/or creative occupations. They found their respondents were ambivalent about why they held multiple jobs: they reported wanting to work in this way and also having to for financial and other reasons. Whereas those in café/restaurant jobs often saw multiple 
job holding as a transitional work arrangement to support themselves and their lifestyle while they pursued other activities, those in creative occupations tended to view multiple job holding as a long-term working arrangement. Despite the negative impacts multiple job holding had on many aspects of their personal and social life, most young people described multiple job holding overall as a positive experience. These findings add to our understanding of the range of work options now taken by younger worker.

Brent Gardiner from Massey University's Palmerston North campus asks what constitutes career success. He presented the initial findings of his $\mathrm{PhD}$ research designed to investigate the subjective perceptions of career success among a sample of younger New Zealanders. Striking amongst his findings is that the 'traditional' notion of career success (advancing up the organisational hierarchy) is well down the assembled list of preferred careers.

\section{Regions and labour market participation}

Dean Rutherford, Shaun Twaddle and Dafydd Davies of the Department of Labour ask how to best measure regional labour market performance. They observe that high performing regional labour markets support the shift towards greater value and improved rewards for businesses, workers and communities. This occurs through gains in productivity achieved through sectoral economies of scale and more efficient regional environments which provide the climate for global skills and talent. They discuss the concept of "high performing" labour markets and suggests a general framework which can. in principle, be applied to any geographic level. The framework identifies the key characteristics of high performing regional labour markets and suggests how these can be measured in terms of supply. demand and markets functionality

Colleen Souness from the Ministry of Social Development and Philip Morrison. from Victoria University of Wellington examine the effect of settlement type on the labour force participation of New Zealand women. They observe that while education, age and reproduction decisions all play a well known role in female labour force participation relatively less is known about role played by the geographic context in which participation decisions are made. Using the Statistics New Zealand reclassification of urban and rural locations to define settlement types they use the 1996 census to demonstrate how place of residence affects the propensity of women to engage in wage labour over and above the other major influences on this decision. After controlling for the demographic composition of the female population. they find that proximity to the metropolitan labour markets changes the volume rather than the incidence of paid work and that participation rates are actually higher for women living in rural areas. They also show how the presence of a partner not only has a major influence on female labour force participation but that the particular influence a partner has also varies by settlement type. They call for a greater explicit awareness of geographic context in models of female labour force participation.

William Cochrane and Jacques Poot from the University of Waikato address the relationship between homeownership and the New Zealand labour market. They observe that since the early 1990s, the proportion of New Zealand households living in owner occupied dwellings has declined markedly from 73 percent in 1991 to 64 percent in 2001 and that over the same period there has been a decline in the census rate of unemployment from 10.5 percent to 7.5 percent, with a further decline in the rate of unemployment since then. While several demand, supply and institutional factors are responsible for the downward trend in unemployment, this paper focuses on a possible connection with homeownership. An extensive theoretical and empirical literature on this hypothesis followed Andrew Oswald's argument that home ownership is detrimental to labour market flexibility because of transaction costs. The present paper reviews earlier findings and then tests the hypothesis with 1986, 1991, 1996 and 2001 census data for 58 labour market areas, using econometric models for panel data. They take account of the endogeneity of homeownership and show that there is some evidence in the New Zealand data that supports the idea that home ownership retards job mobility.

\section{Stress and injury}

Zeenobiyah Hannif, University of Wollongong, New South Wales, Felicity Lamm. University of Auckland, and Karen Lo, and Jeffery Lu explore a new dimension of occupational stress within the New Zealand hospitality industry. Previous research tended to focus on the individual and is frequently located within occupations that are deemed to be stressful, such as nursing and policing. By contrast their paper broadens the scope of analysis by investigating a range of employment factors (i.e. heavy workloads, interpersonal relationships and organisational factors) which can contribute to stress amongst workers. They draw attention to occupational stress amongst workers in the call centre and hospitality industries in order to explore their perceptions of stress, attitudes concerning managing stress and their responses to the inclusion of stress in the Health and Safety in Employment Amendment Act, 2002. They find that working in the hospitality and call centre industries can be stressful and that most workers are vulnerable because of their poor working conditions and low wages. They also show that, consistent with other studies, there is low trade union presence and a high rate of casualisation and staff turnover in each of the industries. At the same time there is a lack of overt conflict between management and workers, with an apparent close alignment of goals between the two parties and a style of management that can be described as unitarist.

Claire Maslin from Statistics New Zealand investigated the measurement of severity of workplace injury. The New Zealand Injury Information Manager. Statistics New Zealand, is scoping possible injury severity thresholds for workplace injury reporting purposes. Severity levels define which injuries to include within different reporting scenarios. Claire investigates methods of measuring workplace injury severity in Australia, the United Kingdom. Canada, and the United States, and the widely accepted academic approach to injury severity levels. She then discusses the application The 'International Classification of Disease-Based Severity Score' (ICISS) to Statistics New Zealand's workplace injury work. 